$\mathrm{Y} \Delta \mathrm{K} 354$

ББК 66.3(0),123

DOI 10.22394/1682-2358-2018-5-37-45

O.V. Romanovskaya, Doctor of Sciences (Law), Professor, Head of the State and Legal Disciplines Department, Penza State University

\section{QUANGO - \\ A LEGAL MODEL \\ FOR INCREASING \\ THE EFFICIENCY OF STATE POWER}

The content of such form of deregulation as a quasi-regulation, which has found its institutional embodiment in the UK in the activities of QUANGO is analyzed. It is shown that QUANGO is a special type of non-profit organizations that perform delegated public functions. The Russian experience of involving QUANGO in the current management activities of the state is considered.

Key words and word-combinations: state power, efficiency, QUANGO, delegation, deregulation.
O.В. Романовская, доктор юридических наук, профессор, заведующий кафедрой государственно-правовьхх дисииплин Пензенского государственного университета (email: pgu-gpd@ yandex.ru)

\section{KBAHГO (QUANGO) - ПРАВОВАЯ MOАЕ $\Lambda \mathrm{b}$ ПОВЫШЕНИЯ ЭФФЕКТИВНОСТИ ГОСУААРСТВЕННОЙ ВААСТИ*}

Аннотация. Анализируется содержание такой формы дерегулирования, как квазирегулирование, которое нашло свое институциональное воплощение в Великобритании в деятельности «Кванго». Показано, что «Кванго» - особый вид некоммерческих организаций, выполняющих делегированные публичные функции. Рассматривается российский опыт вовлечения «Кванго» в текущую управленческую деятельность государства.

Ключевые слова и словосочетания: государственная власть, эффективность, «Кванго», делегирование, дерегулирование.

$\Gamma$

осуаарственная вмасть - многопмановая категория, она явмяется предметом изучения многих социальных наук, вкАючая юриспруденцию. Субъекты осуществления государственной власти - органы, к Аеятельности которых преАъявияются определенные требования, прежде всего их эффективность. Не вызывает сомнения те-

* Публикация подготовлена в рамках подлержанного РФФИ научного проекта № 16-03-50051-ОГН. 
зис о том, что орган власти может действовать законно, Аемократично, но неэффективно. На повышение эффективности органов управления направлена административная реформа, старт которой Аан еще в 2003 г. с принятием Указа Президента РФ от 23 июля 2003 г. № 824 «О мерах по проведению аАминистративной реформы в 2003-2004 годах» [1] .

Проблема эффективности пубцичных институтов постоянно поднимается в научных трудах современных экономистов, по илеологической направленности принадлежащих к мибертарианскому течению. М. РотбарА считац неэффективными ведомства, которые в своей деятельности нацелены на получение финансовых средств из казны, а не на удовцетворенность потребителя - граждан собственной страны [2]. Ф. Хайек (мауреат Нобелевской премии) обвинял государство в громоздкости; по его мнению, только мацые самоорганизованные общества могут эффективно реагировать на быстро меняющуюся действительность (что недоступно бюрократическому аппарату) [3] . Т. Аевитт обосновац теорию третьего сектора [4] , согласно которой некоммерческие организации могут взять на себя выполнение многих публичных функций (преАполагается, что их реализация третьим сектором будет намного эффективнее).

Аибертарианская идея о рассредоточении государственной власти имела Аалеко идущие практические последствия: Аелегирование вмастных полномочий негосударственным организаџиям, появление саморегулируемых организаций, внеАрение сорегулирования в текущую управленческую деятельность.

ОАной из форм повышения эффективности власти считается квазирегумирование, предполагающее опору на квазиорганы. Анализ российской юриАической митературы позволил выявить неоднородность понимания Аанного термина. Его наибольшую детализаџию преАставляет А.А. Петров, но и он не формулирует еАиную концепцию, толкуя квазирегулирование как некую разновидность саморегулирования [5], мибо как квазисаморегулирование, при котором некоторые саморегулируемые организации «вовлекаются в орбиту государственного регулирования» [6] .

В.Е. Чиркин, возрождая теорию юридического миџа публичного права, отмечает, что оно в той или иной мере выполняет функции квазиуправленческого характера [7]. Аанная теория активно развивается в отечественной юриспруденџиип [8-11], но пока не нашиа четкого закрепления в российском законодательстве. Связь квазиуправления и статуса особых юридических миц, выполняющих публичные функщии - непременный признак функционирования квазиорганов. Ввиду отсутствия прямого указания в российских законах на существование юридических миџ публичного права подобные выводы

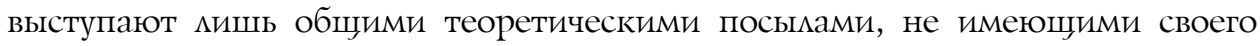
практического применения.

Обращение к зарубежкным источникам также показывает неоднородное отношение к толкованию квазирегулирования. Например, материалы Австрамийской комиссии по реформе права преАставляют конкретный пример: Аобровольный меморандум интернет-провайдеров о фильтрации URL-aАресов, содержащих данные о жестоком обращении с детьми. Аобровольность оАновременно обеспечивается требованиями закона и контролирующими дейс- 
твиями государственных органов [12]. Но и он малосодержателен. Если есть прямое указание закона, то активность подчиненных субъектов вряд $\Lambda$ имеет начала Аобровольности, тем более, когАа речь идет о включении контрольного механизма со стороны органов государственной власти.

Определенность в понимании квазирегулирования наблюдается в управменческой практике Великобритании, гАе его институщиональным вопмощением стало появление особого субътекта - QUANGO (quasi-autonomous non-governmental organisation). Аанная аббревиатура переводится как квазиавтономная негосударственная организация. Автором идеи выступил А. Пайфер, сотрудник Фонда Карнеги, который в своем ежегодном отчете указал на «серую область» между государственным и частным сектором, где используются возможности некоммерческой организации. Он обратил внимание на необходимость привлечения высококлассных специалистов в систему государственного управления, которые отказываются связывать свою судьбу с государственной службой из-за низких зарплат. Потребность в законном способе достойно платить таким спеџиалистам и породила создание некоммерческих организаџий с государственным финансированием и публичными задачами. Благодаря данному отчету в Великобритании была создана рабочая группа, в которую, в частности, вошии, помимо А. Пайфера, А.Р. Хауэм^, депутат парламента от консерваторов, $\Lambda . \AA$. Камлагэн, бывший премьер-министр. Разработанные ими общие начала административной реформы были внедрены в политическую практику страны. Аббревиатура КBAHГO (QUANGO) быма придумана профессором Университета Эссекса Э. Баркером [13] .

В дальнейшем британцы попробовали заменить эту аббревиатуру на другое сокращение - NDPB, которое переводимось как «негосударственный публичный орган». Была представлена даже специальная квалификация NDPB:

- исполнительные (Executive NDPBs), выполняющие отдельные управменческие функции (в том числе связанные с оказанием публичных услуг на коммерческой основе) органов власти;

- консультативные (Advisory NDPBs), осуществляющие независимые экспертные консультации, на основе которых органы государственной вмасти принимают обязательные решения;

- юрисдикционные (Tribunal NDPBs), реализующие надзор за деятельностью отдельных государственных учреждений (например, за пенитенциарными).

Желание унифицировать статус NDPB привело к принятию Акта о публичных органах в 2011 г. (The Public Bodies Act 2011) [14] . Это обосновывалось тем, что общество Аолжно реально преАставцять, какой аппарат Аля реализации публичных служб действует в Великобритании. При этом ставились многоаспектные задачи: повысить прозрачность деятельности таких органов; унифиџировать их статус; ввести жесткую подотчетность, в том чисме парламенту; минимизировать дубцирование пубцичных функций. Под предложенный термин подпадали именно органы, более «привязанные» к публичной службе. Это привело к тому, что «Кванго» стали создаваться в иных формах, чтобы уйти от жесткого контроля, распространяющегося на NDPB. 
Э.В. Талапина подчеркивает: «"Кванго созданы как альтернатива традиционной организаџии государства и наџелены на соџиальную и экономическую регуляцию. В их число входят самые различные организации - консультативные органы, оказывающие научно-техническое содействие министерствам, трибуналы, занимающиеся проблемами миџензирования и разного рода апеммяџионными делами (Великобритания), банковская комиссия, совет по конкуренции, комиссия по биржевым операциям, комиссия по налоговым нарушениям, комиссия по безопасности потребителей (Франџия)» [15, с. 269].

Таким образом, «Кванго» обладает рядом признаков:

- это некоммерческая организаџия;

- она имеет определенный мандат на осушествление некоторых властных полномочий ими пубцичных функций;

- в своей деятельности руководствуется не только первичностью выполнения публичных задач, но и принџипами экономической эффективности;

- на ее работников не распространяются ограничения, характерные Аля государственных служащих;

- оплата труда сотрудников заметно отличается (в сторону увекичения) от вознаграждения государственных служащих;

- действует под эгидой (или в системе) конкретного органа государственной вмасти.

Наибольший расџвет «Кванго» получили в Великобритании с середины 1990-х годов. Пика они достигли в 1998 г., когда их насчитывалось около 700 (точнее, 692) [16]. Значительное число подобных организаций носимо название «Комиссия», главная задача которых заключалась в консультировании по тем или иным вопросам. С середины 2000-х годов численность «Кванго» стала сокращаться. Основная критика в их аАрес заключалась в расходовании бюджетных средств. С учетом того, что «Кванго» явмялись некоммерческими организациями, на них не распространялись ограничения, связанные с государственной службой. Особенно это касалось вопроса расходования финансовых средств. Обвинения касались и скрытого расширения государственного аппарата. При А. Кэмероне появиися даже такой термин, как «квангократия» [17]. В 2003 г. был опубликован отчет, согласно которому было выявлено, что только около $15 \%$ «Кванго» руководствуются открытыми официальными правилами. Назначение на руководящие должности в большинстве случаев осуществляется в «закрытом» типе. В отчете были перечислены десять вопросов, которые Аолжны стимулировать правительственные реформы к развитию демократии в данных структурах:

1. Аействует ки принцип открытости в отношении назначения руководителей «Кванго»?

2. Подотчетны ки эти органы общественности и государству?

3. Осуществляется $\Lambda и$ регулярная проверка их политики, конкретных действий и финансовых расходов?

4. Аолжны ки эти органы опубликовывать публичные отчеты?

5. Осуществляет ии министр, ответственный за деятельность «Кванго», за ними эффективный надзор? 
6. Как действует в отношении «Кванго» парламентский контроль?

7. Могут ми местные органы власти влиять на политику «Кванго» ?

8. Какова ответственность за надмежашее исполнение возможенных функщий?

9. Представцяют ми руководители «Кванго» общественность (в широком смысле слова)?

10. Свободны ки руководители «Кванго» от ненадмежашего влияния и помитической предвзятости?

В џелом отчет охарактеризовац «Кванго» как непрозрачные («замкнутый мир») [18] .

В 2010 г. опубликованы финансовые результаты проверки «Кванго», показавшие излишнюю расточительность в оплате труда ряда служащих: 4337 служащих получияи вознаграждение, превышающее 100 тыс. фунтов стерцингов; 973 сотрудника получици вознаграждение более 150 тыс. фунтов стерлингов; 106 служащих получили вознаграждение более 250 тыс. фунтов стерлингов. Предана огласке тройка самых высоко оплачиваемых сотрудников «Кванго»: П. Батчер (767 тыс.); Р. Гисби (742 тыс.); С. Кирби (741 тыс.) [19]. Понятно, что указанные доходы заметно отличались от Аолжностных окмадов государственных служащих. После этого было объявлено о Аиквидации 192 «Кванго» [20] .

В российской управленческой практике внедряются опредеменные механизмы, позволяющие проводить аналогии с британскими «Кванго». Например, в соответствии с постановлением Правительства РФ от 28 июля 2018 г. № 885 [21] контроль и наАзор в сфере образования и науки осуществмяет Федеральная служкба по надзору в сфере образования и науки (Рособрнадзор). ОАно из основных полномочий Аанной службы связано с государственной аккредитацией образовательных организаций. В то же время непосредственная экспертиза проводится экспертами, привлекающимся федеральным государственным бюджетным учреждением «Национальное аккредитационное агентство в сфере образования» на основе гражданско-правового договора.

Отталкиваясь от понятия «квазирегулирование» и зарубежного опыта, можно с уверенностью заключить, что классическим примером квазирегулятора в России выступает государственная корпорация. Из всей совокупности ныне существующих особое место занимает государственная корпорация «Росатом», статус которой определен Федеральным законом от 1 декабря 2007 г. № 317-Ф3 «О государственной корпорации по атомной энергии “Росатом"» [22].

Возникновение особого субъекта права связано с тем, что в 1999 г. появимось новое видение некоммерческих организаџий: были внесены изменения в Федеральный закон от 12 января 1996 г. № 7-Ф3 «О некоммерческих организациях» [23]. В соответствии с появившейся в нем ст. 7.1 государственной корпорацией признается не имеющая чменства некоммерческая организаџия, учрежденная Российской Федерацией на основе имущественного взноса и созАанная Аля осуществления соџиальных, управленческих или иных общественно полезных функщий. В рамках общей реформы был создан ряд госкорпораций (часть из них уже киквидирована, например «Олимпстрой»), в числе которых ГК «Росатом». 
Обращение к первым статьям Закона от 1 декабря 2007 г. № 317-Ф3 показывает, что в ГК «Росатом» происходит совмешение публичных и частноправовых начал. Так, ст. 2 Закона четко характеризует ее как «уполномоченный орган управления», «наделенный полномочиями от имени Российской Федераџии осуществлять государственное управление использованием атомной энергии». Указание на государственное управление как основное предназначение корпорации происходит в Законе неоднократно. Статья 4 определяет цели деятельности «Росатома», которые совпадают с основными функциями органов исполнительной вмасти (проведение государственной политики; нормативно-правовое регулирование; государственные услуги; управление государственным имуществом). Иные статьи также подчеркивают пубцичный статус корпорации: государственная регистрация ее нормативных актов, использование печати и бланков с изображением Государственного герба России. С Аругой стороны, «Росатом» - участник преАпринимательских соглашений, аккумулирующий сеть коммерческих организаџий, действующих по канонам частного права.

Таким образом «Росатом» - гибриА, включающий в себя эмементы некоммерческой организации, органа государственной вмасти и субъекта преАпринимательской деятельности. Отсутствие разработки единой конџепџии подобных участников общественных отношений приводит к формированию комплекса правовых претензий, в центре которых нарастающая тенденџия коммерџиализаџии государственной деятельности [24]. Подобное характерно и для стран Западной Европы, где введен в оборот специальный термин - «приватизаџия государственной власти», поА которым как раз понимается вовлечение негосударственных организаџий в круг субъектов публичного управления [25]. Есть претензии и к иному виАу переАачи пубцичных функций и полномочий в руки частного сектора - дерегулированию, которое, в свою очередь (например, в США), рассматривается как форма приватизаџии власти - как долгосрочная стратегия расширения частного сектора за счет сокращения общественного сектора [26]. Кстати, именно данная стратегия мегла в основу рэйганомики, где одним из ключевых столпов выступало именно дерегулирование, воспринимаемое как «средство мечения» избыточного государственного регулирования. В Великобритании аналогичная политика обозначена термином «тэтчеризм».

Современная ситуация, складывающаяся в США и странах Евросоюза, показывает, что все большую актуальность приобретают иные меры (противоположные дерегулированию): протекционизм, централизаџия управления, усияение государственного контроля и Аругие. Происходит постепенный отказ от парадигмы дерегулирования, что и приводит к пересмотру параметров оценки эффективности государственного аппарата. Применительно к «Кванго» в Великобритании это обусловило сокрашение их числа и постановку поА более жесткий государственный контроль. В США также проводятся специальные кампании против дерегулирования и вовлечения некоммерческих организаџий в сферу публичного управления. Американский ученый А.Аж. Эми создал свой интернет-проект против дерегулирования [27]. В оАной из его

42 Bulletin of the Volga Region Institute of Administration • 2018. Vol. 18. № 5 
публикаций приведены масштабные негативные следствия ухода государства из определенных сфер регулирования: разлив нефти в Мексиканском заливе, вспышки сальмонемлы на пишевых комбинатах, ипотечный кризис. По его мнению, дерегулирование - ошибочная фимософия, получившая максимальное распространение при администрации Аж. Буша-младшего (автор использует экспрессивный вывоА - «аА сломался»). А.Аж. Эми проводит аналогии и спрашивает, как бы отнесся гражданин, если министром обороны стал бы отъявленный пацифист, а директором ФБР - аАвокат мафии? Согласно представлениям ученого именно такая политика Аж. Буша привела к разбамансированности всей государственной системы (ее «саботажу»): ключевые управленческие должности стали занимать мица, чьи интересы кардинально отмичались от функций, возмагаемых на органы власти («мисы стали охранять курятник»). А.Аж. Эми приводит тактику таких «Аис»-управленџев по постепенному уводу государственного органа от регулирования: постоянная задержка в принятии необходимых государственных правил; сокрашение собственного бюджета; отсутствие активности в текушей управленческой деятельности; снижение сумм штрафов за неисполнение регулирующих правил и сокращение числа контролеров; игнорирование мнений экспертных советов; пропаганда отказа от госрегулирования; учет мнения только миц, подмежащих

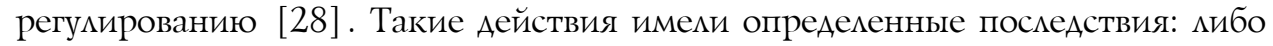
полный отказ от мер публичного воздействия на общественные отношения, мибо реформа государственного аппарата по принџипу британских «Кванго».

Вовлечение зарубежного опыта в российскую управленческую практику происходит постоянно, но, к сожалению, без должной оџенки всех возможных последствий. Так, создание госкорпораций происходимо без внятной конџепции, что и повлекмо за собой череду обвинений в несовершенстве их статуса и создании почвы Аля коррупџии и увода бюАжетных денег в «частные руки». В конечном итоге А.А. Медведев, будучи Президентом РФ, провозгласил курс на отказ от госкорпораций, который, правда, не был доведен до конца. В то же время, 2 октября 2016 г., вступил в силу Федеральный закон от 3 июля 2016 г. № 236-Ф3 «О публично-правовых компаниях в Российской Федерации и о внесении изменений в отдельные законодательные акты Российской Федерации» [29]. Аанный нормативный акт вводит в оборот новую организационно-правовую форму юридического мица - публично-правовую компанию, которая, по замыслу законодатемей, должна прийти на смену госкорпорации. При этом внятного объяснения такой смены так и не получено от миц, причастных к разработке Федерального закона. Это привело мишь к созАанию оАной публично-правовой компании - Фонда защиты прав граждан, участников Аолевого строительства. Отметим, что в соответствии с Гражданским кодексом РФ и Федеральным законом «О некоммерческих организациях» фонА - самостоятельный виА юридического мица.

Такие метания происходят на фоне неприятия конџепџии юридических миџ публичного права, которая уже на протяжении пятнадџати цет активно обсуждается в российской юридической науке, но не нашла своего закрепления в офиџиальных актах государства. Аналогичная ситуаџия происходит и 
с делегированием государственно-властных полномочий. Эта проблема при Аальнейшем внедрении «Кванго» в России будет нуждаться в своем разрешении. Можно констатировать, что де-факто делегирование присутствует. Отчасти этот опыт мегализован решениями Конституџионного Суда РФ (в отношении нотариальных палат, саморегулируемых организаций арбитражных управляющих и оценщиков). Отчасти делегирование происходит по умолчанию, как в примере с госкорпораџией «Росатом». Но подобные практические примеры не отменяют потребности в выработке единой концепции такого делегирования. Законодатель должен четко понимать, в каких случаях оно может быть осуществлено, в каких пределах и в какой форме. Случаи демегирования властных полномочий должны носить экстраординарный характер и обеспечиваться действенным государственным механизмом контроля. В этом случае публичный статус у субъекта частного права Аолжен быть во многом схож со статусом органа государственной вмасти. Компетенция такого субъекта Аолжна подчиняться принџипу: дозволено только то, что прямо предписано законом. Реализация государственных полномочий - не просто право, а обязанность, невыполнение которой является преступным деянием.

Отсутствие единой конџепџии приводит к хаотичным изменениям отрасцевого законодательства, что сопровождается неприятием со стороны ученыхспециалистов, появлением пробелов, противоречий. В то же время следует заключить, что дерегулирование, квазирегулирование нуждается в серьезной оценке при проведении административной реформы. Британский опыт создания «Кванго» требует серьезной оџенки. Несмотря на жесткие обвинения, в Великобритании от них полностью не отказались, хотя определенная волна критики, казалось, должна была привести к их полному искоренению. Именно взвешенный анализ зарубежного опыта позволит отечественному законодателю учесть те ошибки, которые уже были выявлены в реальной управленческой практике.

\section{Библиографический список}

1. СЗ РФ. 2003. № 30. Ст. 3046.

2. Rothbard Murray N. For a New Liberty: The Libertarian Manifesto. 2006.

3. Хайек $Ф$. Право, законодательство и свобода: Современное понимание либеральных принципов справедливости и политики. М., 2006.

4. Levitt T. The Third Sector: New Tactics for a Responsive Society. AMACOM, 1973.

5. Петров Д.А. Саморегулирование в системе социального регулирования общественных отношений // Российская юстиция. 2016. № 11. С. 68-71.

6. Петров Д.А. Квазисаморегулируемые организации в сфере предпринимательства // Государственная власть и местное самоуправление. 2015. № 4. С. 54-59.

7. Чиркин В.E. Юридическое лицо публичного права. М., 2007.

8. Кутафин О.Е. Субъекты конституционного права Российской Федерации как юридические и приравненные к ним лица. М., 2007.

9. Лафитский В.И. К вопросу о юридических лицах публичного права // Журнал российского права. 2011. № 3. С. 103-108.

10. Романовская О.В. Совет муниципальных образований - юридическое лицо публичного права // Российская юстиция. 2014. № 8. С. 5-9.

44 Bulletin of the Volga Region Institute of Administration • 2018. Vol. 18. № 5 
11. Романовская О.В. О юридических лицах публичного права // Гражданин и право. 2015. № 5. C. 29-40.

12. Codes and Co-regulation. URL: https://www.alrc.gov.au/sites/default/files/pdfs/publications/11_codes_and_co-regulation.pdf

13. Interviewee: Alan Pifer. URL: http://www.columbia.edu/cu/lweb/digital/collections/oral_ hist/carnegie/pdfs/alan-pifer.pdf

14. The Public Bodies Act. URL: http://www.legislation.gov.uk/ukpga/2011/24/contents

15. Талапина Э.В. Публичное право и экономика. М., 2011.

16. Economic Research Council. URL: http://quangos.ercouncil.org:80/faq/answer, $0,1,0,0,0$ quangos_economic_research_council.html

17. Morris N. One by one, the quangos are abolished. But at what cost? // The independent. 2010. 27 July. URL: https://www.independent.co.uk/news/uk/politics/one-by-one-the-quangos-areabolished-but-at-what-cost-2036175.html

18. Quangos and quangocrats. URL: http://www.democraticaudit.com/our-work/other-work/ quangos/quangos-and-quangocrats/

19. Public Sector Rich List - Quangos. URL: https://www.taxpayersalliance.com/psrl_quangos

20. Q\&A: What is a quango? URL: https://www.bbc.com/news/uk-politics-11405840

21. СЗ РФ. 2018. № 32 (Ч. ІІ). Ст. 5344.

22. СЗ РФ. 2007. № 49. Ст. 6078.

23. СЗ РФ. 1996. № 3. Ст. 145.

24. Романовский Г.Б. Принципы правотворческой политики: проблемы реализации // Российский журнал правовых исследований. 2015. № 2. С. 45-50.

25. Schnee P., Unterberg S. Privatisierung von Polizeiaufgaben. Ein Rьckzug des Staates? URL: http://www.deutschlandfunk.de/privatisierung-von-polizeiaufgaben-ein-rueckzug-des-staates.724. de.html?dram:article_id $=360178$

26. Публичные финансы и финансовое право: сборник научных трудов к 10-летию кафедры финансового права Высшей школы экономики / Р.Е. Артюхин, Ю.В. Гинзбург, Ю.В. Гинзбург [и др.]; под ред. А.Н. Козырина. М., 2012.

27. Government is Good. URL: http://governmentisgood.com

28. Stealth Deregulation: The Untold Story. URL: http://governmentisgood.com/articles. php?aid $=15 \& \mathrm{p}=2$

29. СЗ РФ. 2016. № 27 (Ч. І). Ст. 4169. 